\title{
IBN KHALDUN (1332-1406) E UM OLHAR MUÇULMANO SOBRE A PENÍNSULA IBÉRICA
}

\author{
Elaine Cristina Senko \\ Orientação: Marcella Lopes Guimarães
}

PALAVRAS-CHAVE: Ibn Khaldun; historiador muçulmano; Al-Andaluz.

As análises sobre a Península Ibérica na perspectiva de um muçulmano da Idade Média podem ganhar novo entendimento valendo-se das concepções sugeridas por Edward Said, Albert Hourani e Roberto Marin Guzmán. Na obra Orientalismo, Said ${ }^{1}$ desmascara o recorrente discurso ocidental sobre o Oriente, o qual aponta a estigmatização realizada pelos europeus acerca dos muçulmanos, ressaltando a importância do papel do "outro". Assim, poderíamos recorrer ao estudo de uma mentalidade individual, do ponto de vista islâmico, a fim de esclarecer e discutir alguns equívocos de interpretações.

A consciência da alteridade existente entre muçulmanos e cristãos no século XIV, nosso recorte temporal, possibilita-nos compreender de forma mais abrangente a produção erudita daquele período, aqui, sobretudo, focalizada na cultura islâmica. Optamos por adentrar esse ambiente de saber por meio da obra autobiográfica de Abu Zaid Abd'ul-Rahman Ibn Khaldun (1332-1406). Nesta, além de presenciar as ações de Reconquista cristã, o autor demonstra-se mais interessado em colocar por escrito suas observações a respeito da sociedade, da filosofia e da política de seu tempo.

A produção de saber promovida por Ibn Khaldun é demonstrada pelo autor em sua Autobiografia, na qual lemos inclusive a experiência relatada por ele dentro do espaço agitado da política, tanto do norte de África quanto da Península Ibérica. O estudo e análise da Autobiografia tornam-se interessantes sob

\footnotetext{
${ }^{1}$ SAID, Edward W. Orientalismo: o Oriente como invenção do Ocidente. Tradução de Tomás Rosa Bueno. São Paulo: Companhia das Letras, 1990.
} 
diferentes aspectos: demonstra-nos as escolhas políticas dos soberanos muçulmanos e cristãos no momento anterior e posterior a Reconquista; permite-nos uma aproximação do pensamento histórico de Ibn Khaldun; possibilita adentrarmos a sabedoria andaluza; e, também, é uma fonte medieval que pode e deve ser valorizada como uma contra-voz de autoridade para o período tardo-medieval, levando-se em consideração o paradigma ocidental.

Além disso, o contato com o personagem histórico Ibn Khaldun e sua obra demonstra o pensamento e as ações de um erudito muçulmano que enxergava uma realidade política islâmica em crise. Essa visão do autor pode ser explicada em termos do contexto histórico no qual estava inserido, marcado por vários acontecimentos, dentre os quais destacamos: o contato das dinastias árabes com os mongóis e, também, com os cristãos (em processo de avanço sob territórios antes muçulmanos); a difícil manutenção e controle, por parte dos árabes, de algumas das principais tribos por eles dominadas; e a gradativa infiltração, no interior da administração muçulmana, do otomano vindo da Anatólia.

Devido a todos esses aspectos conjunturais, podemos entender que Ibn Khaldun tentou resguardar a essência de AlAndaluz, a qual foi necessária no ambiente de Túnis como exemplo da resistência do poder islâmico, bem como para a preservação de uma memória cultural. Ele recorre a esse espaço de valor para nos apresentar e realçar a sua formação, de modo a propagar a sua erudição e definir o foco mantenedor do mundo em que viveu. Deste modo se faz necessária a explicação da existência de Al-Andaluz, pois a "umma" (comunidade muçulmana) teria uma forma perene se fosse concatenada à erudição. Tal como salienta Roberto Marin Guzmán, Ibn Khaldun viveu um período de crise do Império Islâmico no século XIV, e isso pode nos fornecer dados sobre o seu próprio pensamento descrito em suas obras ${ }^{2}$.

${ }^{2}$ MARÍN GUZMÁN, Roberto. Estado de la cuestión sobre la Mahdiyya: Estudio de las fuentes del movimiento Mahdista en el Sudán. Editor Roberto Marín Guzmán. 1ªedição. Costa Rica, 2009, p. 28. 
Percebemos no objeto de nosso estudo, a erudição de Ibn Khaldun, um meio pelo qual podemos entender a história do mundo muçulmano de sua época. Assim, propomos uma atenta observação à nossa problemática, a qual busca, através dos relatos efetuados por Khaldun, fragmentos de momentos importantes da política e cultura desenvolvidas em $\mathrm{Al}$-Andaluz, bem como a provável continuidade da sabedoria dessa região para o norte de África.

Os objetivos desse estudo foram evidenciar, a partir da leitura crítica da Autobiografia de Ibn Khaldun, como esse historiador identificava a formação do Magreb tardo-medieval entre a decadência política do presente e um glorioso passado vivido em Al-Andaluz. Ao mesmo tempo, também contribuímos na revisão da bibliografia que focaliza a presença de árabes na Península Ibérica e no norte de África. Essas duas ações, uma em busca do entendimento do processo político daquele momento no Islã e a outra, de diálogo com a bibliografia acerca dos referidos contextos locais, promoveram a compreensão para o nosso estudo do espaço dominado politicamente pelos árabes e, depois com seu estabelecimento, como foi desenvolvida a erudição em ambas as regiões.

A carreira erudita de Ibn Khaldun, paralela àquela exercida oficialmente por ele em diversos sultanatos, foi a mola propulsora de suas obras. A política de sua época era dominada ainda pelos conflitos no norte de África entre a dinastia dos Hafsidas (1228-1574) e a dinastia dos Marínidas (1196-1465). Além dessas duas grandes dinastias, as quais Ibn Khaldun serviu, podemos destacar a importante tribo do norte de África, os Banu Hilal. No entanto, o homem político Ibn Khaldun soube negociar em prol de seus interesses, mantendo uma posição a todo tempo próxima ao poder - pois era isso o que lhe garantia triunfar com a ação de sua pena, promovendo o saber.

A obra de Ibn Khaldun foi escrita entre 1374-1378 e é dividida em: Autobiografia de Ibn Khaldun e seus Prolegômenos Muqaddimah. De acordo com Richard Max de Araújo ${ }^{3}$, Ibn Khaldun,

${ }^{3}$ ARAÚJO, Richard Max de. Ibn Haldun: o estudo de seu método à luz da idéia de decadência nos Estados do Ocidente muçulmano medieval. Dissertação de 
no ano de 1382 na cidade de Túnis, fez uma revisão da sua Muqaddimah e deixou um manuscrito da obra ao sultão hafsida da região, Abu'l-Abbas. Logo depois, quando Ibn Khaldun estava no Cairo, enviou outra cópia do manuscrito para o sultão marínida de Fez, Abu Faris. Em 1397 dedicou uma terceira cópia do manuscrito ao sultão mameluco Malik al-Zahir Barquq. As revisões feitas por Khaldun se realizaram até 1402 (manuscrito n. 1936 de Atif Efendi de Istambul). A tipologia das fontes para o nosso estudo é a Autobiografia $^{4}$ (pertencente como anexo nessa edição brasileira ao primeiro livro da Muqaddimah) e a Muqaddimah ${ }^{5}$ (dividida em três livros). As referidas obras que utilizamos em nossa pesquisa foram publicadas entre as décadas de 1950 e 1960 pelos pesquisadores brasileiros José Khoury e Angelina Bierrenbach Khoury, os quais realizaram a transliteração direta dos manuscritos em língua árabe para o português.

A leitura e a investigação da Autobiografia de Ibn Khaldun se realizou, primeiramente, como um autêntico roteiro para se estabelecer a cronologia da vida do autor, desde seus antepassados até o final de seus dias. Essa fonte histórica deve ser manuseada com cautela, pois se trata de um documento legitimador produzido pelo erudito Ibn Khaldun, o qual fez uma seleção de momentos que correspondiam aos seus anseios tanto na vida pública quanto na vida privada. Entretanto, a fonte é interessante e reveladora na medida em que favorece uma interpretação que é apresentada somente por meio dos relatos do "eu". A escrita do gênero autobiográfico nesse caso correspondia a uma necessidade de Ibn Khaldun se justificar perante

mestrado: Universidade Estadual de Campinas, Instituto de Filosofia e Ciências Humanas. Campinas, 2004, p. 32-34.

${ }^{4}$ KHALDUN, Ibn. Autobiografia. In: Muqaddimah - Os prolegômenos (tomo I). Tradução integral e direta do árabe por José Khoury e Angelina Bierrenbach Khoury. São Paulo: Instituto Brasileiro de Filosofia, 1958.

${ }^{5}$ KHALDUN, Ibn. Muqaddimah (tomo I, II, III). Tradução integral e direta do árabe por José Khoury e Angelina Bierrenbach Khoury. São Paulo: Instituto Brasileiro de Filosofia, 1958-1960. 
suas ações e a sua escolha de fatos ao narrar nos permite analisá-lo como ele gostaria de ser reconhecido.

Quando Ibn Khaldun revela a angústia de estar ligado a guerras ou aos cargos da administração que assumiu, verificamos a preocupação do historiador com a sua erudição e percebe-se uma tradição de sua família que lhe ensinou a sempre estar ao lado do poder, mesmo quando os governantes fossem substituídos. Essa política realizada pela família dos Khaldun teria seu ponto de partida nas formas de poder na Península Ibérica e era uma adaptação e sobrevivência nos altos escalões no Norte de África.

Dessa forma, passamos a estudar os antepassados da família Khaldun na Península Ibérica e acabamos por encontrar também dados sobre o contexto político islâmico na região. A Autobiografia de Ibn Khaldun nos demonstra que seu autor possuía uma origem remota na Península Arábica através da tribo dos Hadramut. O representante desta tribo na época era Uail Ibn Hojr, o qual foi, segundo o historiador Ibn Khaldun, um dos Companheiros do Profeta (século VII). Logo após ocorreu a migração de parte dessa tribo para a Península Ibérica. Nesse momento, dos séculos XI-XII a família Khaldun se encontrava ao lado da dinastia dos Almorávidas e, depois com a substituição destes, passou a compartilhar do poder com os Almôadas. Os Khaldun se estabeleceram inicialmente em Carmona e depois em Sevilha.

Conforme a descrição de Ibn Khaldun, em meados do século XIII, o sultão Abu Zacaria tornou-se soberano de Ifríkya (Túnis). Logo depois da morte desse, Al-Andaluz mergulhou na subversão e o rei cristão Fernando III (1217-1252) aproveitou a ocasião e atacou a região de Fronteira (formada pela planície que se estende de Córdoba, Sevilha e Jaen). O sultão de Granada realizou acordos com Fernando III e estabeleceu-se nessa região da Península Ibérica. Assim a família Khaldun partiu para Ceuta e após se fixou em Túnis.

Em um segundo passo de nossos estudos adentramos os relatos de Ibn Khaldun sobre seu próprio tempo de vida, e logo pudemos identificar algo interessante: ele vincula os diferentes 
momentos de sua vida com os cargos públicos que assumira ao longo dela. Ibn Khaldun reafirma, ao longo da narrativa, que as funções assumidas por ele demonstravam que era um homem preparado, ou seja, que possuía grande conhecimento para a sociedade de seu tempo. Nesse momento do nosso trabalho, passamos então a discorrer sobre o que o letrado islâmico informa acerca de si próprio.

Na adolescência, em Túnis, foi escrivão do parafo real do sultão Abu Ishac (consistia em ter controle da administração do sultão). Em 1352, Khaldun parte para Tebessa com o objetivo de seguir os sábios marínidas pelo Norte da África. Em Fez (1354), Ibn Khaldun foi convidado pelo sultão Abu Inan para ser seu secretário do parafo (Khaldun não gostou dessa posição porque não honrava sua descendência, ou seja, seus antepassados nunca ocuparam tal cargo) e integrante das reuniões dos sábios. Já no ano de 1359, o substituto do sultão Abu Inan, o sultão Abu Salem, colocou Khaldun no cargo de secretário particular e depois no de madhalim (o reparador das injustiças).

Em Sevilha, no ano de 1363, Khaldun foi encarregado da ratificação de paz entre o rei Pedro, o Cruel, e os emires de AlAndaluz. Em 1365, retornando ao norte da África, mais especificamente para a cidade de Bugia, Khaldun assumiu o cargo de hajib do sultão Abu Abd Allah. Khaldun também participou de expedições militares de conquista do sultão de Tlemcen, Abu Hammu.

No ano de 1374, Khaldun encontrou com os Aulad Arif, tribo árabe que patrocinará o ambiente necessário para o historiador muçulmano escrever suas obras Muqaddimah e Autobiografia. Já em 1383, no Cairo, Khaldun ministra aulas na Mesquita de Al-Azhar e assume o cargo de cádi malikita.

A partir desse panorama acerca da vida de Ibn Khaldun, construímos um mapa único da movimentação de Ibn Khaldun, partindo de estudos acerca de cada cidade em que o historiador muçulmano viveu, perpassou simplesmente ou aquelas em que exerceu por um determinado período um poder local definido. Este 
instrumento tornou possível um olhar mais abrangente sobre o autor, um agente da história, e o mundo em que viveu, marcado por muitos conflitos de caráter político.

Dessa forma, por conta da nossa necessidade de verificar os cargos assumidos por Khaldun relatados por ele em sua Autobiografia, construímos ainda uma série de mapas detalhados, tendo como base o anterior (de aspecto geral), visando o melhor entendimento dos interesses do historiador Ibn Khaldun nos territórios por onde passou. A amplitude das viagens de Ibn Khaldun tinha um caráter da procura por governos estáveis que se dispusessem ao patrocínio de seu saber. O interessante é que constatamos também a grande vontade dos sultões em receber Khaldun. Tal fato demonstra, o que também orientou nosso pensamento, a estreita relação entre poder e saber, este último sendo uma espécie de elemento legitimador do primeiro. Assim, foi graças ao seu saber, adquirido ao longo de sua vida, que Khaldun foi intensamente procurado pelos homens de poder. Por isso, demonstrou-se sempre desejoso em estudar cada vez mais, pois o saber era sinônimo, na concepção que ele sempre defendeu, de importância e ascensão na vida pública.

Destarte, foi necessário fazer a recomposição dos traços da singularidade da erudição desenvolvida na região de Al-Andaluz e destacar sua "continuidade" no norte de África através da formação de Ibn Khaldun, essência de nosso trabalho. Além disso, devemos destacar como tal processo forjou o letrado muçulmano, para que enfim este apresentasse o modelo de ensino que lhe foi incumbido, nos possibilitando entender a sua própria identidade e representatividade nas cortes por onde passou. Nessa direção indicamos a autenticidade da erudição de Ibn Khaldun por sua formação específica com mestres andaluzes e magrebinos em Túnis. A madrasa (escola) de formação de Ibn Khaldun foi a malikita, que era a escola oficial em Al-Andaluz e tinha por lições: leitura específica do Alcorão, o Tafassi (sobre tradições escritas no Muwatta que servia de base ao sistema da jurisprudência malikita), o Tamhid, o 
Tashil (sobre regras gramaticais), Mukthaçar (resumo de jurisprudência) e também foram ensinados a Ibn Khaldun as poesias citadas no Kitab Al-Agani.

Dentro desse estudo também dialogamos com Albert Hourani, que sinaliza ao longo do seu livro Uma história dos povos árabes ${ }^{6}$ uma visão da história dos árabes concomitante à importância histórica dos escritos eruditos de Ibn Khaldun. A influência khalduniana em Hourani é de fácil percepção, pois que o historiador inglês se utiliza do método histórico de Ibn Khaldun, resultado da formação erudita do referido muçulmano, para descrever os diversos momentos de uma história de conquista do poder pelos árabes. Nosso estudo possui, portanto, uma proposta de caráter reflexivo que permite o diálogo entre a cultura islâmica e o poder. A construção dessa sabedoria muçulmana realizada por Ibn Khaldun legitima sua própria imagem histórica, pois que a relevância de seus escritos sustenta o estudo desse letrado na Idade Média num ambiente efetivo de ruído estridente de espadas.

Portanto, apontamos que o letrado Ibn Khaldun pertenceu à esfera das cortes muçulmanas medievais, na qual ocupou cargos específicos ao lado do poder - posições essas legitimadas pela sua própria erudição. Dessa forma, Ibn Khaldun conquistou notoriedade em sua época por ser um sábio que, depois de aprender as lições obrigatórias, se dedicou a desenvolver seus estudos de forma autônoma. A fonte nos preparou para um aprofundamento do gênero narrativo histórico autobiográfico na Idade Média, nos recepcionou para o contexto da Reconquista cristã na Península Ibérica, permitiu o estudo do contexto das dinastias muçulmanas em Al-Andaluz e no Magreb, dos cargos políticos do Império islâmico e forneceu indícios primordiais para se examinar os estudos desenvolvidos nas "madrasas" (escolas) andaluzas ao lado do prolongamento das idéias da "falsafa" (filosofia árabe) provenientes do Islã Clássico na Idade Média. Para se compreender a postura assumida por Ibn Khaldun

\footnotetext{
${ }^{6}$ HOURANI, Albert. Uma História dos povos árabes. Trad. de Marcos Santarrita. São Paulo: Companhia das Letras, 2006.
} 
como erudito e propagador efetivo de uma cultura híbrida originária de Al-Andaluz nos baseamos na produção de suas fontes e no vestígio efetivo que elas nos apresentaram, tais como a importância dada à região e sua formação de mestres que foram os do nosso historiador. Ibn Khaldun se propôs a ser um erudito que se dedicou ao estudo da História tendo por base suas observações sobre a sociedade e política de seu tempo. O presente estudo nos indica uma continuidade de análise acerca da especificidade da história pertencente à Idade Média, com o foco no grupo dos muçulmanos e suas relações de poder a partir dos escritos de um letrado excepcional. 